Röwekamp, Marion, Die ersten deutschen Juristinnen. Eine Geschichte ihrer Professionalisierung und Emanzipation (1900-1945)

\title{
Marie-Bénédicte Vincent
}

\section{(2) OpenEdition}

Édition électronique

URL : http://journals.openedition.org/ifha/6547

DOI : $10.4000 /$ ifha. 6547

ISSN : 2198-8943

Éditeur

IFRA - Institut franco-allemand (sciences historiques et sociales)

Référence électronique

Marie-Bénédicte Vincent, « Röwekamp, Marion, Die ersten deutschen Juristinnen. Eine Geschichte ihrer Professionalisierung und Emanzipation (1900-1945) », Revue de l'IFHA [En ligne], Date de recension, mis en ligne le 01 janvier 2012, consulté le 22 septembre 2020. URL : http://journals.openedition.org/ifha/ 6547 ; DOI : https://doi.org/10.4000/ifha.6547

Ce document a été généré automatiquement le 22 septembre 2020.

(CIFHA 


\title{
Röwekamp, Marion, Die ersten deutschen Juristinnen. Eine Geschichte ihrer Professionalisierung und Emanzipation (1900-1945)
}

\author{
Marie-Bénédicte Vincent
}

1 Voilà une somme appelée à rester durablement la principale référence sur l'histoire des premières femmes juristes en Allemagne (et de manière secondaire en Autriche). L'auteure a consulté tous les centres d'archives possibles (une soixantaine au total, sans compter les archives privées et la vingtaine d'entretiens oraux réalisés au début des années 2000), lu un très grand nombre d'autobiographies et une littérature secondaire fournie (la bibliographie fait une cinquantaine de pages). Ce doctorat dirigé par Winfried Schulze aboutit à une synthèse impressionnante, écrite dans une langue claire caractérisée par sa rigueur scientifique.

2 Le plan de l'ouvrage reprend les principales étapes des carrières juridiques féminines de la première moitié du XXe siècle. La première partie est consacrée à l'ouverture aux femmes des études de droit dans la décennie précédant la Première Guerre mondiale. La deuxième partie analyse, dans un contexte international, l'accès différé des femmes aux métiers juridiques (notamment la loi de 1922 leur permettant de passer le second examen d'Etat qualifiant aux métiers de juge et d'avocat). La troisième partie évoque l'exercice par les femmes juristes des responsabilités professionnelles, tandis que la quatrième partie traite de leurs engagements para-professionnels (notamment dans le mouvement féministe et dans la sphère sociale). Enfin la dernière partie aborde la césure de l'avènement du nazisme, qui entraîne l'exclusion quasi complète des femmes des métiers juridiques en 1933/35, et pas seulement des juives.

3 Le talent de l'auteure est de parvenir à nous faire revivre le parcours de ces pionnières, grâce à une plongée saisissante dans les autobiographies, qui éclairent de l'intérieur l'histoire institutionnelle et politique ou les données statistiques. Ainsi au sujet des études universitaires, on apprend que les premières étudiantes ont été ignorées de 
leurs camarades et même de certains de leurs professeurs hostiles à l'émancipation féminine et ne se sont jamais vues adresser la parole. Les autobiographies viennent aussi nuancer les césures attendues : par exemple, la loi de 1922 ne s'est pas traduite par une hausse immédiate du nombre d'étudiantes immatriculées en droit. Un des chapitres les plus riches est celui qui évoque le quotidien professionnel des femmes juristes : le silence glacial des salles d'audience découvrant que l'homme de loi n'est ... pas un homme, ou alors la difficulté pour les femmes ouvrant un cabinet d'avocat à conserver après leur mariage leur nom de jeune fille par lequel elles sont identifiées auprès de leur clientèle (le code civil interdisant les doubles noms). Ces voix qui parlent à travers les autobiographies ont un visage grâce aux photos d'identité en appendice, du moins pour les premières juristes entrées au service de l'État (Maria Munk, etc.) et les premières avocates. On découvre aussi avec effroi celui des femmes compromises dans le nazisme, ainsi Käthe Petersen qui, engagée sous Weimar dans le travail social, travaille en 1933 sur les lois eugénistes qui conduisent à la stérilisation des " asociaux » ou handicapés : un exemple qui montre que les femmes ne sont pas seulement des victimes (Opfer), mais aussi des Täter. Le texte volumineux s'enrichit d'un index des noms propres.

4 Marie-Bénédicte Vincent (université d'Angers) 